\title{
EFECTOS PERSONALES DEL DIVORCIO RESPECTO DE LOS HIJOS. DE ROMA AL CÓDIGO CIVIL ESPAÑOL
}

Obra da prof ${ }^{\mathrm{a}}$. dr ${ }^{\mathrm{a}}$. Carmen López-Rendo Rodríguez, Ridrom (on line) 9, 2012, p. 249-270. Disponível em: <http://www. ridrom.uclm.es>. ISSN 1989-1970.

clrendo@uniovi.es

Resenha pela prof ${ }^{\mathrm{a}}$. dra. Teresa Duplá Marín Catedrática de Direito Romano e professora de Direito Civil (Escuela Superior de Administración y Dirección de Empresas (ESADE/URL). Professora associada na Universidade de Barcelona.

La Dra. Carmen López-Rendo nos presenta una valiosa aportación en torno a uno de los temas más complejos del Derecho de familia, cual es, el de la regulación de la guarda y custodia de los menoresen caso de divorciodelos padresy, más concretamente, eldelos criterios deatribucióndelamisma. A dicha complejidad hay que añadir su rabiosa actualidad, ya que estamos ante una de las cuestiones más debatidas por la doctrina y la jurisprudencia en los últimos años, fruto, sin duda, del aumento de las crisis y rupturas matrimoniales (o en su caso de las uniones o parejas), y como consecuencia de ello, del incremento de situaciones que, en nuestra sociedad, precisan de una regulación y de una solución que, ante todo, respete el principio fundamental del interés superior del menor ${ }^{1}$. Basta para ello acercarse a los datos estadísticos con el fin de comprobar ambas realidades. En este sentido, los datos publicados por el $\mathrm{INE}^{2}$, nos muestran un claro y evidente incremento, año tras año de estos casos, desde la promulgación de la ley del divorcio - Ley 30/1981 de 30 de julio por la que se modifica la regulación del matrimonio en el Código Civil y se determina el procedimiento a seguir en las causas de nulidad, separación y divorcio -, y hasta la nueva regulación calificada de "exprés" - Ley 15/2005 de 8 de julio por la que se modifican el Código Civil y la Ley de Enjuiciamiento Civil en materia de separación y divorcio ${ }^{3}$-, datos que nos sitúan entre los diez primeros países miembros de la Unión Europea con mayor número de divorcios. Por todo ello y antes de nada, mi felicitación a la autora por la elección del tema y su aportación a esta importante problemática práctica.

Como nos muestra la Dra. Lopez-Rendo, basta echar la vista atrás para comprobar que estamos ante una realidad - que incluso me atrevería a calificar de "problema" de nuestra sociedad de finales del s. XX y principios del s. XXI - cuyo origen hay que ubicarlo en sociedades muy antiguas, ya que, tanto el divorcio como la regulación de sus consecuencias, fueron objeto

\footnotetext{
${ }^{1}$ Vid. al respecto, por todos, el interesante trabajo de RIVERO HERNANDEZ, El interés del menor, $2^{\mathrm{a}}$ ed., Madrid, 2007.

2 Instituto Nacional de Estadística.

${ }^{3}$ Partimos de una realidad que a principios de los años noventa se sitúa en una cifra cercana a los 28.000, cifra que va incrementando hasta casi duplicarse en el año 2004 (en concreto 52.591), para experimentar en el año 2005, y como consecuencia de la entrada en vigor de la nueva ley que facilita el acceso al divorcio, un incremento cercano a los 94.000 casos (93.536), incremento que se repite a lo largo de los siguientes dos años hasta alcanzar la cifra máxima, en el año 2006, de 141.317. A partir de este momento, y con cierta seguridad como consecuencia del inicio de una incipiente crisis económica, esta cifra ha ido descendiendo lentamente y hasta situarse alrededor de los 110.000 casos en el año 2009/10. Hay que apuntar que estas cifras nos colocan entre los 10 primeros países de la UE en mayor número de divorcios. Vid. al respecto www.ine.es.
} 
ya de una concreta e interesante regulación en época romana clásica tardía, como queda detallado por la autora en su estudio. Dicho esto, creo que se hace preciso matizar que los supuestos de divorcio a los que alude la autora en el ámbito del Derecho romano pueden ser interpretados en un sentido amplio, es decir, como casos de ruptura de una relación matrimonial, y por tanto, en ellos cabría incluir también los actuales supuestos de separación de las partes existiendo menores y con la necesidad de determinar el régimen de guarda y custodia de los mismos (incluidos, por tanto, los alimentos) $)^{4}$.

El trabajo de la Dra. Lopez-Rendo, siendo fiel al título del mismo, se estructura en dos claros apartados precedidos de una breve introducción: el primero de ellos dedicado al análisis de la regulación de las consecuencias del divorcio en época romana (pp. 1-14); y el segundo, y más extenso - dividido a su vez en cinco sub apartados: glosadores y comentaristas; Humanismo, iusnaturalismo racionalista y usus modernus pandectarum; Derecho patrio y Recepción en el código civil vigente -, centrado en el proceso de recepción de esta regulación hasta la época actual (pp. 14-44).

Comienza la autora con una, a mi juicio, muy oportuna y necesaria introducción acerca de la estructura familiar romana, centrada en la figura del Pater Familias y con un parentesco, el agnaticio, ab initio, muy distinto al actual. El origen y la evolución de la patria potestas centran con acierto su atención, siendo absolutamente necesarios para poder dar entrada y comprender la regulación romana de los efectos de un posible divorcio. Esto es, una de las piezas clave de los cambios experimentados en torno a esta materia por la regulación actual tiene su razón de ser, justamente, en la patria potestad dual de nuestros tiempos, extraña en época romana donde el poder sobre los hijos se concentra siempre en manos del Pater Familias. Esto justifica, sin duda, y respecto de algunos supuestos concretos recogidos por las fuentes en el trabajo, la complejidad de la regulación romana de estas cuestiones, puesto que se tenía que partir siempre de la idea de que el titular de la patria potestad tras el divorcio - salvo casos concretos de extinción/suspensión de la misma - iba a ser el padre. También, y como excepción a ese poder omnímodo del pater, el posible desdoblamiento, ya en Roma, de la titularidad y el ejercicio de la patria potestad que, sin recibir la denominación como en la actualidad de guarda y custodia, es evidente que recogen las fuentes mostradas por la autora. Con dos diferencias fundamentales respecto de la regulación actual que creo que es oportuno tener en cuenta: por un lado, que hoy, alcanzada la igualdad de los padres en torno a la titularidad de la patria potestad ( $\mathrm{art} .154 \mathrm{cc}$ ), la guarda y custodia no compartida, en caso de divorcio, se ejerce por uno de los titulares de la patria potestad, cosa que no puede ocurrir en los supuestos contemplados en las fuentes romanas en caso de desdoblamiento, por la imposibilidad jurídica citada de que la mujer/madre sea titular de la misma; y por otro, la evidente actual limitación temporal de la titularidad de la patria potestad, derivada de su vinculación a la emancipación fundamentalmente u otros criterios determinados por la ley, situación esta que, en Roma, es algo distinta, fruto de la diferente organización de la estructura familiar.

Como ya he apuntado, la Dra. López-Rendo nos ofrece una visión sobre la regulación existente al respecto a partir de la época clásica tardía, momento en que la autora muestra las primeras fuentes que regulan los efectos de la ruptura matrimonial, en concreto en D. 43.30.1.1 y 3 (Ulp. Lib. LXXI ad Ed.), D. 43.30 .3 .5 y 6 (Ulp. LXXI ad Ed.) y D. 43.30 .5 (Ven. Lib. IV Interd.), textos directamente vinculados con los interdictos de liberis exhibendis item ducendis que, como apunto en su día TORRENT ${ }^{5}$, más allá de interdictos posesorios, deben ser calificados como interdictos de protección al pater en los casos en que los hijos se encontraban

\footnotetext{
${ }^{4}$ En este sentido CJ 5,24,1 en el que se utilizan los términos divortio y matrimonio separato.

${ }^{5}$ En Diccionario de Derecho Romano, Madrid, 2005, p. 476.
} 
bajo el poder de terceros. La siguiente noticia nos la ofrece a través de C.5.24 (Divortio facto apud quem liberi morari vel educari debeant) de los emperadores Diocleciano y Maximiano en respuesta a Celestina, y en el que se impone el arbitrio judicial pleno y libre para la atribución de la guarda y custodia de los hijos en caso de falta de acuerdo de las partes. Al que hay que añadir C.5.25 (De alendis liberis ac parentibus) en el que se recoge la existencia de la obligación de dar alimentos no solo a los hijos, sino también a los padres y, en su caso, la posibilidad de reclamarlos judicialmente. Pero va a ser Justiniano, a través de su Novela $113^{6}$ en la que regula el divorcio contencioso, capítulo VII, y el de mutuo acuerdo, capítulo X, y ofreciendo en los capítulos VIII y IX una relación de posibles causas de la separación, el que cierre la evolución de la regulación jurídica de los efectos del divorcio en época romana introduciendo, como acertadamente apunta la autora, una serie de criterios, de carácter subjetivo, la culpabilidad en el divorcio, y objetivo, la riqueza o nivel económico de los progenitores, que van a ser criterios clave en esta materia con el paso del tiempo, en concreto, y en nuestro país, hasta la última reforma del año 2005, antes mencionada. Interesa, en este sentido, apuntar la firmeza y claridad de los criterios establecidos ya que se llega a afirmar que, incluso para el supuesto de separación de mutuo acuerdo, los mismos tienen que tenerse en cuenta.

Quiero destacar de esta primera parte el interesante aparato bibliográfico al que hace referencia la autora que sintetiza las principales obras y autores en torno a esta temática, así como el valioso y amplio complemento que nos ofrece de fuentes jurídicas y literarias romanas, herramienta de información muy interesante para cualquier estudioso que quiera acercarse a esta materia.

Respeto de la segunda parte del trabajo quisiera subrayar la claridad en la presentación sintética de la recepción de esta regulación hasta la época de la codificación, a la que la Dra. Lopez-Rendo acompaña de un estudio minucioso posterior a través de los distintos proyectos de Código Civil hasta la regulación incluida en éste, y en el que nos informa acerca del mantenimiento, o no, de los criterios en la determinación de la guarda y custodia, así como de las novedades que van apareciendo en este sentido. Tras la publicación del Código Civil en 1889 la autora recoge las principales novedades en esta materia a tener en cuenta, la Ley del divorcio de 1932 y la Ley de 24 de abril de 1958, señalando con acierto que el momento importante de cambio en relación a la materia en estudio va a producirse en nuestro país con la publicación de la ley divorcio en 1981 y posteriormente con la de 2005. Desde ese momento, tal y como hemos indicado, el incremento de rupturas va a poner de manifiesto, no solo la importancia de los efectos personales y económicos de éstas - sobre todo en los supuestos en los que existen menores - sino también, la debilidad de la propia regulación ante la complejidad de la misma realidad social y pluralidad casuística que la autora también recoge en su trabajo, y del que se desprende su dominio practico de la materia ${ }^{7}$. A esto hay que añadir la intención, cada vez más creciente, del legislador por impulsar un cambio de cultura en este tipo de conflictos con el fin de procurar el recurso por las partes a los medios alternativos de resolución de conflictos (ADR), en concreto a la Mediación familiar ${ }^{8}$, recurso que puede agilizar y facilitar la toma de acuerdos

6 En el texto griego, como apunta la autora, Novela 117.

7 Vid. por todos, interesante trabajo de CARPI, R., Los gastos extraordinarios en las pensiones de alimentos a los hijos: un análisis jurisprudencial. Diario La Ley (7270), 2009, pp. 1-19, en el que la autora pone de manifiesto la complejidad de la situación actual centrada en el amplio arbitrio judicial a la hora de determinar el reparto de los gastos extraordinarios en las pensiones de alimentos. ROMERO COLOMA, A: El concepto de gasto extraordinario de los hijos y su problemática jurídica.Diario La Ley, Nº 8000, 2013.

8 Vid. por todos, DUPLÁ MARIN,T (coord.), El régimen jurídico de la Mediación familiar en España. Análisis de la normativa autonómica, Santiago de Compostela, 2012. 
en tema de guarda y custodia, y ser, en definitiva, mucho más provechoso para los progenitores y los menores. De todo lo cual podemos afirmar que, sin duda alguna, en esta materia la realidad ha superado a la ficción 9 .

No quiero finalizar estas líneas sin manifestar mi satisfacción ante aportaciones de este tipo en las que se evidencia, ante todo, la capacidad de síntesis y de análisis de la autora para recoger, en unas pocas páginas, la esencia de una figura a lo largo de cerca de veinte siglos de la evolución histórica. Contribuciones de este tipo, en las que se realiza un estudio diacrónico de una institución concreta son hoy, más que nunca, y ante la velocidad de los cambios y de nuestra sociedad, muy enriquecedores y necesarios ya que ofrecen al lector una visión clara, a la vez que completa, de la evolución histórica y de los cambios que permiten una reflexión sobre la materia en estudio más allá del simple análisis de la normativa o jurisprudencia actuales. Con ellos se sigue dotando, a la moderna ciencia del derecho, de herramientas de análisis jurídico, fundamentales para cualquier estudio o reflexión jurídica que se precie.

Data de recebimento: nov/2012 - Data de aprovação: fev/2013

\footnotetext{
${ }^{9}$ Realidad que se sigue superando en nuestros días como consecuencia de los importantes cambios producidos en el ámbito del Derecho de Familia y de la familia en general. La ampliación del concepto de familia, centrado anteriormente en la familia matrimonial, ha dado entrada a otros modelos y realidades familiares como las uniones de hecho o parejas estables, los matrimonios de homosexuales, las step families o familias reconstituidas y las mono parentales, que sin duda, incrementan la complejidad del tema que nos ocupa. A ello hay que sumar, en los últimos años, por un lado, la influencia ejercida por la actual crisis económica que ha hecho que se tengan que revisar y cambiar algunos de los criterios que la jurisprudencia fue asentando a lo largo de los años 80 y 90 , y por otro, la inserción laboral de la mujer que ha ejercido una influencia importante en la remodelación de la estructura interna familiar y el rol de cada uno de los miembros. En este sentido, baste tener en cuenta la actual tendencia al establecimiento, impensable hace tan solo unos años, como preferente de la custodia compartida en los casos en que esta es posible y supone un beneficio para el menor. Vid. por todos, PEREZ MARTIN y PEREZ RUFIAN, La crisis económica y la pensión alimenticia en RDF, nº 57, 2012, pp. 25-46.
} 